\title{
Antimicrobial Activity of Different Essential Oils against Aspergillus flavus and Klebsiella pneumoniae Isolated from Respiratory Tract
}

\author{
W. A. El-Shouny, Eman H. F. Abd El-Zaher, Samya A. Shabana ${ }^{\#}$ and \\ Olaa A. Mohammed \\ Botany Department, Faculty of Science, Tanta University, Tanta, Egypt.
}

\begin{abstract}
SSENTIAL oils from Cinnamomum verum (Cinnamon), Lavandula angustifoli (Lavender), Lepidium virginicum (Peppergrass oil), Zingiber officinale (Ginger) and Cinnamomum camphora (Camphor) have been investigated for their antifungal and antibacterial activities against 6 fungal isolates of Aspergillus flavus and 25 bacterial isolates of Klebsiella pneumoniae. The sensitivity was determined using agar well diffusion method and the inhibition zones were compared with the standard drug itraconazole for fungi and Amikacine for tested bacteria. The tested essential oil showed a wide spectrum of inhibition against the tested isolates. Treating the Klebsiella pneumoniae, with cinnamon essential oil led to an external changes, irregular cell shape and disintegration of bacterial cell wall under transmission electron microscope. GC-MS technique was used for cinnamon essential oil; the composition of cinnamon oil was dominated by cinnamaldehyde. The in vivo efficacy of cinnamon essential oil in treatment of Klebsiella pneumoniae in mice lungs was proven.
\end{abstract}

Keywords: Essential oils, Antifungal, Antibacterial, GC-MS, TEM.

\section{Introduction}

The drug resistant pathogens are one of the most serious to successful treatment of microbial diseases. The use of medicinal plants became the first medicines is global phenomenon. In Nature, essential oils play an important role in the attraction of insects to promote the dispersion of pollens and seeds or to repel other ones. In addition, essential oils may also act as antifungal, antibacterial, antiviral, insecticides and herbicides (Bakkali et al., 2008). This search intends to respond to the increasing resistance of pathogenic microbes to antibiotics and there is increasing acquaintance acceptability of the use of herbal drugs in today's medical practice. There is no effective machinery to regulate manufacturing practices and quality standards (Kunle et al., 2012). It is important to find out the particular microorganisms for which the herbal extracts are active (Pesavento et al., 2015). Essential oils and other extracts of plants have evoked interest as sources of natural products concerning their potential uses as alternative remedies for the treatment of many infectious diseases (Nor et al., 2016). Essential oils possess antibacterial, antifungal, antiviral insecticidal and antioxidant properties against microorganisms (Lakehal et al., 2016). Essential oil exhibited maximum inhibitory activity against respiratory disease causing microbes like Klebsiella pneumoniae, Streptococcus pneumoniae, Haemophilus influenzae, and P. aeruginosa (Skocibu et al., 2004).

There is a belief that herbal medicines might be effective benefit in the treatment of certain diseases, that are free from side effects (Bouzidi et al., 2016). The detection of some of these biological properties needed for the survival of plants has also been the base for searching similar properties for the combat of several microorganisms responsible for some infectious diseases in humans and animals (Cornelia et al., 2017).

The objective of this study was to determine the antifungal and antibacterial effects of five plant essential oils against fungal and bacterial respiratory tract infections.

\section{Materials and Methods}

Test organisms

Six fungal isolates were obtained from patient had cough and breathing problems which had bronchial asthma. Aspergillus was isolated and maintained on Sabouraud Dextrose Agar (SDA) medium for 7 days at $28 \pm 2^{\circ} \mathrm{C}$ with 
adding $0.05 \mathrm{~g} / \mathrm{L}$ chloramphincol as antibacterial agent (Mahmoud et al., 2011). The isolate was identified microscopically under light microscope at Mag 40x according to Moubasher (1993). Pure cultures of 25 tested bacterial isolates used in the study were obtained from cultivation of medical specimen of sputum from patients admitted to Tanta University hospital, Egypt. These specimens were taken from the Central Lab. of the hospital. The specimen were cultivated on nutrient broth overnight at $37^{\circ} \mathrm{C}$ for $24 \mathrm{~h}$, then subcultured on nutrient agar, macConkey agar and blood agar for another $24 \mathrm{~h}$. The investigated isolates were identified morphologically and biochemically according to Bergey's Manual (Garrity, 2001). The bacterial isolate was maintained on nutrient agar slants and stored at $4^{\circ} \mathrm{C}$ prior to use.

\section{Molecular identification of the fungal isolate and accession number \\ DNA extraction}

The mycelium of Aspergillus was scratched off the surface of $2 \%$ Potato Dextrose Agar PDA Petri plate. The mycelia $(50 \mathrm{mg})$ were ground using a mortar and pestle. DNA was extracted from the powdered tissue using i-genomic DNA extraction Mini Kit (INTRON Biotechnology, Inc, Cat. No. 17371) according to manufacturer's instructions. The eluted DNA was stored at $-20^{\circ} \mathrm{C}$ (Denning et al., 1990).

\section{PCR condition}

Amplification of internal transcribed spacer (ITS) region was conducted in thermal cycler (C1000TM Thermal Cycler, Bio-RAD) using ITS4 (5'-TCCTCCGCTTATTGATATGC-3') and ITS5 ( 5 'GGAAGTAAAAGTCGTAACAAGG-3 ') primers (White et al., 1990). The following parameters were used: 35 cycles of $94^{\circ} \mathrm{C}$ for 30 sec, $51^{\circ} \mathrm{C}$ for $1 \mathrm{~min}, 72^{\circ} \mathrm{C}$ for $1.5 \mathrm{~min}$, and a final extension at $72^{\circ} \mathrm{C}$ for $3 \mathrm{~min}$. Each PCR mixture $(25 \mu \mathrm{l})$ as follow, $(1 \mu \mathrm{l})$ of nucleic acid, $1 \mu \mathrm{l}$ of each primer $(10 \mathrm{pmol}),(12.5 \mu \mathrm{l})$ of GoTag ${ }^{\circledR}$ Master Mix (Promega Corporation, USA) and 9.5 $\mu \mathrm{l}$ of nuclease free water (Promega). $15 \mu \mathrm{l}$ of all PCR products were analyzed by electrophoresis through a $1 \%$ agarose gel, stained with ethidium bromide.

\section{Sequence analysis of the ITS region}

The amplified PCR amplicon was submitted by City of Scientific Research and Technology Applications, New Borg El Arab City, Alexandria, Egypt to Macrogen Company (Seoul, Korea) to be sequenced. The DNA nucleotide sequence was analyzed using DNA BLASTn (NCBI). Pair wise and multiple DNA sequence alignment were carried out using Clustal W (1.82) (Thompson et al., 1994).

Identification of the most sensitive bacterial isolate by using the Biomerieux VITEK ${ }^{\circledR} 2$ system

The tested bacterium mostly affected by the cinnamon essential oil was cultured on the appropriate liquid nutritional medium and was incubated overnight at $37^{\circ} \mathrm{C}$. Then the cultures were centrifuged at $3000 \mathrm{rpm}$ for $20 \mathrm{~min}$, washed with sterile saline solution and the turbidity of the bacterial suspensions was adjusted with a densitometer to match that of a McFarland 0.5 standard in $0.45 \%$ sterile sodium chloride solution, then the VITEK 2 cards were filled with bacterial suspension and manually loaded into the VITEK 2 system.

\section{Essential oils}

Five natural essential oils; Cinnamon, Pepper grass oil, Lavender, Camphor and Ginger were purchased from Captain Company in the local market and different dilutions of the oils were prepared $(1: 1,1: 3,1: 5$ and $1: 10 \mathrm{v} / \mathrm{v})$ using Dimethyl sulphoxide (DMSO).

Antifungal and antibacterial susceptibility assay of isolated fungi and bacteria

Amphotericin B, itraconazole, Fluconazole, ketoconazole, Metronidazole and Nystatin were used as positive antifungal controls for fungal isolates. The plates were incubated at $25^{\circ} \mathrm{C}$ for $2-3$ days. The results were expressed in terms of the diameters of inhibition zones and the mean were then calculated. All experiments were carried out in triplicates, and the mean of 3 readings was calculated. Antibiotics susceptibility was assessed using the disc diffusion method for all bacterial isolates as recommended by the Clinical and Laboratory Standards Institute (CLSI, 2014) using fourty selected antibiotic discs (Bioanalyse, Turkey) from different classes of antibiotics. These antibiotics ( $\mu \mathrm{g} /$ disc) were Imipenem (10), Clavunic acid (10), Amikacin (30), Streptomycin (10), Gentamicine (10), Chloramphenicol (30), Azithromycin (15), Cephradine (30), Cefaclor (30), Cefotaxime(30), Cefadroxil(30)Ceftazidime (30), Levofloxacine (5) and Amoxicillin (30). The test was carried out by placing $6 \mathrm{~mm}$ diameter of paper disc containing antibiotic onto a microbial inoculated plate. Bacteria were incubated at 30 $37^{\circ} \mathrm{C}$ for $16-24 \mathrm{~h}$ and the inhibition zones were measured after incubation period. Each inhibition zone around the antibiotic disc was measured and values were interpreted as sensitive or resistant 
for each antibiotic by referring to performance standards for antimicrobial susceptibility testing (CSLI, 2014).

\section{Antifungal and Antibacterial activities}

Antimicrobial activities of essential oils were evaluated for their antifungal activity against Aspergillus spore suspensions $\left(10^{6} \mathrm{cfu} /\right.$ $\mathrm{ml}$ ) was introduced separately and thoroughly mixed with $20 \mathrm{ml}$ of Sabouraud Dextrose Agar (SDA) in triplicates (Anibijuwon \& Udeze, 2009). A sterile $6 \mathrm{~mm}$ cork borer was then used to punch hole in the inoculated agar and the agar was then removed. Wells were filled with $100 \mu \mathrm{l}$ of essential oils, Demso used as negative control to determine antibacterial activity of essential oils by agar well diffusion method, petri- dishes with $20 \mathrm{ml}$ of MuellerHinton agar were prepared, inoculated with $\left(10^{6} \mathrm{cfu} / \mathrm{ml}\right) .100 \mu \mathrm{l}$ of a $24 \mathrm{~h}$ broth culture of test bacteria. Wells of $6 \mathrm{~mm}$ diameter each were made and filled with $100 \mu \mathrm{l}$ of essential oils. The zones were measured in $\mathrm{mm}$. To measure the best essential oils that showed the highest inhibition activity against the tested fungi and bacteria, various dilution of the essential oil $(1: 1,1: 3,1: 5$ and $1: 10 \mathrm{v} / \mathrm{v})$ were assayed against the tested fungal and bacterial isolates.

\section{Gas chromatography mass spectroscopy}

Cinnamon essential oil content was examined by gas chromatography, Mass spectroscopy in Claurs 580/560S. Work was carried out by using acolumn $30.0 \mathrm{~m}$ x $250 \mu \mathrm{m}$, Rtx-5MS (crossbond 5\% diphenyl 95\% dimethyl polysiloxane), Perkin Elmer Company in Central Lab, Tanta University, equipped with heated FID. The GC conditions were employed using Helium as carrier gas $(0.8$ $\mathrm{ml} / \mathrm{min}$ ) and the temperature program was $100^{\circ} \mathrm{C}$ for $1 \mathrm{~min}$, followed by an increase of $120^{\circ} \mathrm{C} / \mathrm{min}$ to $220^{\circ} \mathrm{C}$ for the remainder of the run. Detector and injection point heaters were $275^{\circ}$ and $250^{\circ} \mathrm{C}$, respectively, and typically 0.1 or $1.0 \mu$ was injected at a 20: 1 split (Uniyall et al., 2012).

\section{Effect of cinnamon essential oil on the cell of} Klebsiella pneumoniae

In this experiment, transmission electron microscope (T.E.M.) was used to follow the mode of action of $20 \%$ cinammon oil in DMSO. The cellular change of Klebsiella pneumoniae was compared with control (without Cinammon essential oil). Preparation of bacterial sample for examination by TEM was achieved according to Spuur (1969) and Ellis \& Griffiths
(1974) at the TEM. Unit in Faculty of Medicine, Tanta University, Egypt.

\section{Efficacy of cinnamon oil on infected mice}

In vivo efficacy of cinnamon oil on mice infected with Klebsiella pneumoniae and bred in animal house unit, Faculty of Science, Tanta University were divided in to Four groups (n $=6 /$ group). The first group of mice was let healthy without infection as negative control, The second group of mice served as positive control (6 mice) injected intrapretonially with $0.04 \mathrm{ml}$ of $10^{7} \mathrm{cfu} / \mathrm{ml}$ suspension of Klebsiella pneumoniae then injected intrapretonially with $0.1 \mathrm{ml}(0.9 \%) \mathrm{NaCl}$. The third group was injected intrapretonially with $0.04 \mathrm{ml}$ of $10^{7}$ $\mathrm{cfu} / \mathrm{ml}$ suspension of Klebsiella pneumoniae then treated with amikacin as antibacterial drug , Fourth group of mice was injected intrapretonially with $0.04 \mathrm{ml}$ of $10^{7} \mathrm{cfu} / \mathrm{ml}$ suspension of Klebsiella pneumoniae and treated with a mixture of cinnamon oil and $(0$. $9 \%) \mathrm{NaCl}(0.03 \mathrm{ml}+0.07 \mathrm{ml})$. The treatment was continued every $24 \mathrm{~h}$ for six days. then 24 $\mathrm{h}$ of the final dose injection, the mice lungs were removed under aseptic condition.

\section{Histology}

Histological examination was done in Histology Department, Faculty of Medicine, Tanta University by fixing mice lungs tissues in $10 \%$ formalin in solution, processed and embedded in paraffin wax. Lung tissues blocks were sectioned at $5 \mu \mathrm{m}$ thick and stained with Haematoxylin and Eosin (H \& E) (Mahmoud et al., 2011). All lung section samples were photographed under Carl Zeiss Axiostar light microscope connected with digital Canon camera soft program zoom browser at $40 \mathrm{x}$ mags in central laboratory, Zoology Department, Faculty of Science, Tanta University, Egypt.

\section{Statistical analysis}

The data were statistically processed to estimate the mean \pm standard deviation (SD) of triplicates, and using the one way analysis of variance (ANOVA) to analyze the effect of different essential oils on the antimicrobial activity. All data were analyzed according to the Statistical Package for Social Sciences (SPSS) version 16.0 (SPSS Inc., Chicago, IL). At $P$ value of $<0.01$ was considered to be statistically highly significant. 


\section{$\underline{\text { Results }}$}

Sensitivity of Aspergillus flavus to antifungal agents

Six fungal isolates were obtained from patient had cough and breathing problems which had bronchial asthma admitted to Tanta University Hospital, Egypt. The microscopic identification revealed that the isolates were belonging to Aspergillus flavus. According to the antifungal sensitivity of the isolated fungi, the resistance percentage ranged from $0 \%$ to $100 \%$; that 6 isolates were resistant to Fluconazole (FLC) Metronidazole (MT), (100\% resistance of isolates) and 4 isolate resistant to Amphotericin B (AP), (66\% resistance of isolates). But no isolates were resistant to Itraconazole (IT), Ketoconazole (KT) and Nystatin (NS) (0\% resistance of isolates). The best antifungal were Itraconazole (IT) was selected as a positive control to compare its antifungal activity with antifungal activities of essential oils used in this study (Table 1).

TABLE 1. Antifungal resistance percentage of the tested fungal isolates.

\begin{tabular}{lccc}
\hline Antifungal antibiotics & Concentration $\boldsymbol{\mu g}$ /disk & $\begin{array}{c}\text { Antifungal resistant isolates } \\
\text { No. }\end{array}$ & $\begin{array}{c}\boldsymbol{\%} \\
\text { (AP)Amphotericin B }\end{array}$ \\
(FLC)Fluconazole & 50 & 4 & 66.6 \\
(IT)Itraconazole & 25 & 6 & 100 \\
(KT)Ketoconazole & 30 & 0 & 0 \\
(MT)Metronidazole & 10 & 0 & 0 \\
(Nystatin (NS & 5 & 6 & 100 \\
\hline
\end{tabular}

Number of tested fungal isolates $=6$

The antifungal activities showed in Table 2, Cinnamon essential oil was effective against Aspergillus spp. with inhibition zones (23-30 $\mathrm{mm})$ and ginger oils revealed (13- $16 \mathrm{~mm}$ ), however Camphor oil gave inhibition zone from $(14$ to $27 \mathrm{~mm})$. Whatever Lavender oil gave $(14-15 \mathrm{~mm}$ while no inhibition zone with
Pepper oil against Aspergillus spp. isolates The tested concentration of oils different from (1:1; $1: 3 ; 1: 5 ; 1: 10 \mathrm{v} / \mathrm{v})$, while Cinnamon essential oil showed $28 \mathrm{~mm}$ and ginger gave $10 \mathrm{~mm}$ at concentration $(1: 10 \mathrm{v} / \mathrm{v})$ but no inhibition with Camphor oil, Pepper oil and Lavender oil at concentration $(1: 10 \mathrm{v} / \mathrm{v})$ against Aspergillus isolates. DMSO used as negative control.

TABLE 2. Effect of different essential oils on A. flavus isolated from patients with respiratory tract infections.

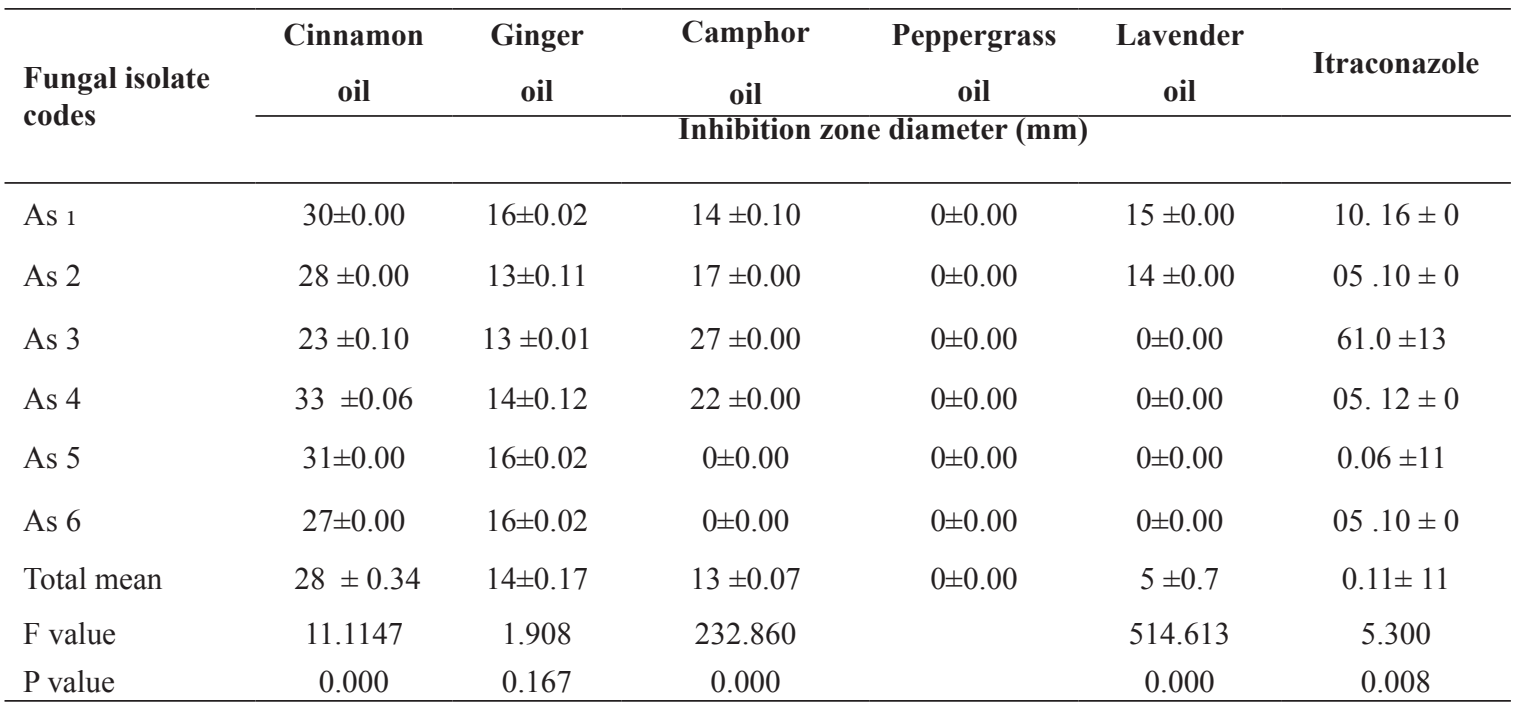

DMSO: represents the negative control $=0 \mathrm{~mm}$. 


\section{Molecular Identification}

As shown in Fig. 1 and 2. The sequence analysis of $18 \mathrm{~S}$ rRNA gene of tested fungal isolates AS4 revealed $99 \%$ similarity with Aspergillus flavus strain AX05 GU966494. Accessed from Gen Bank. Fungal strain belong to section flavus such as A. oryzae, A. parvisclerotigenus and exhibited slightly lower similarity (around 99\%) and appeared in aspirate. Thus the identified fungal isolate AS4 as Aspergillus flavus RES 7 (Accession No.: KY026062) in the gene bank.

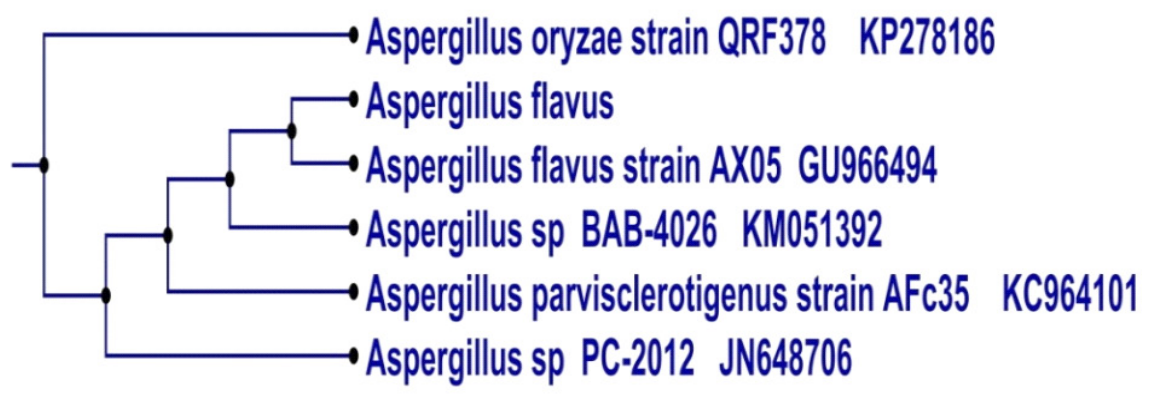

Fig. 1. Phylogenetic tree of 18S rRNA gene sequences of Aspergillus flavus RES 7 (Accession No.: KY026062).

1 tccgtaggtgaacctgcggaaggatcattaccgagtgtagggttcctagcgagcccaacc

61 tcccatccgtgtttactgtaccttagttgcttcggcgggccegccattcatggccgccgg

121 gggctctcagccccgagcccgcgeccgecggagacaccacgaactctgtctgatctagtg

181 aagtctgagttgattgtatcgcaatcagttaaaacttccaacaatggatctcttggttcc

241 ggaatcgatgaagaacgcagcgaaatgcgataactagtgtgaattgcagaattccgtgaa

301 tcatcgagtctttggacgcacattgcgccccctggtattccggggggcatgcctgtccga

361 gcgtcattgctgcccatcaagcacggcttgtgtgttgggtcgtcgtcccctctccggggg

421 ggacgggccccaaaggcagcggcggcaccgcgtccgatcctcgagcgtatggggctttgt

481 caccggctctgtaggcccggccggcgcttgccggacgcaaatcaatcttttccaggttga

541 cctcggatcaggtagggatacccgctgaacttaagcatatcaataagcggagga

Fig. 2 . The nucleotide sequence of 18SrRNA gene of Aspergillus flavus 594 pb

Antimicrobial activity assay

Pure cultures of 25 tested bacterial isolates used in the study were obtained from cultivation of clinical specimen of sputum from patients admitted to Tanta university Hospital, Egypt. According to the antibiotic sensitivity of the isolated bacteria, the resistance percentage ranged from $60 \%$ to $100 \%$; that 10 isolates were resistant to Clavunic acid (AML) (100\% resistance of isolates). and 24 isolate resistant to Chloramphenicol (CL), Azithromycin (AZM), Cephradine (CE), Cefaclor (CEC), Cefotaxime (CTX), (96\% resistance of isolates). But 23 isolates were resistant to Streptomycin (S), Cefadroxil (CFR) Ceftazidime
(CAZ) Amoxicillin (AMC) (92\% resistance of isolates). However, all the twenty two isolates were resistant to Streptomycin(S), Levofloxacine (LEV), Imipenem (IPM) $(88 \%$ resistance of isolates). 15 isolates were resistant to Amikacin (AK) $(60 \%$ resistance of isolates), then it was selected as a positive standard control to the antibacterial activities of essential oils used in this study. Amikacin is a broad spectrum antibiotic and its cost is very low for any patient. Also resistance percentage of Amikacin against the tested bacteria was $60 \%$ where 15 isolates were resistant to this drug (Table 3). 
TABLE 3. Antibiotic sensitivity test.

\begin{tabular}{lcccc}
\hline \multirow{2}{*}{ Antibiotic Class } & Antibiotics & Concentration $\boldsymbol{\mu g}$ / & \multicolumn{2}{c}{ Resistant isolates } \\
disk potency & No. & \% \\
\hline \multirow{3}{*}{ Aminoglycoside } & Amikacin (AK) & 30 & 15 & 60 \\
& Gentamicine (CN) & 10 & 17 & 68 \\
\hline a penicillin & Streptomycin (S) & 10 & 23 & 92 \\
\hline b-lactamase inhibitor & Amoxicillin (AMC) & 30 & 23 & 92 \\
\hline Carbapenems & Clavunic acid (AML) & 10 & 25 & 100 \\
\hline \multirow{3}{*}{ Cephalosporins } & Imipenem (IPM) & 10 & 22 & 88 \\
\hline \multirow{2}{*}{ Cephem } & Cephradine (CE) & 30 & 24 & 96 \\
\hline Fluoroquinolones & Cefaclor (CEC) & 30 & 24 & 96 \\
\hline Macrolide & Cefotaxime (CTX) & 30 & 24 & 96 \\
\hline Phenicol & Cefadroxil (CFR) & 30 & 23 & 92 \\
\hline
\end{tabular}

Number of tested bacterial isolates $=25$.

The results of the antibacterial activities presented in Table 4 showed that Cinnamon essential oil was effective against Klebsiella pneumoniae with inhibition zones $19-30 \mathrm{~mm}$ and ginger oils recorded 11- $20 \mathrm{~mm}$, however, Camphor oil gave inhibition zone from 11 - 20 $\mathrm{mm}$, while Pepper oil showed inhibition zone from 11 to $23 \mathrm{~mm}$, and Lavender oil gave $10-15$ $\mathrm{mm}$ against Klebsiella pneumoniae. The tested concentration of oils different from $1: 1 ; 1: 3 ; 1: 5$; $1: 10 \mathrm{v} / \mathrm{v}$, Cinnamon essential oil showed $18 \mathrm{~mm}$ at concentration $1: 10 \mathrm{v} / \mathrm{v}$ but no inhibition with Ginger oil, Camphor oil, Pepper oil and Lavender oil was observed at concentration $1: 10 \mathrm{v} / \mathrm{v}$ against Klebsiella pneumoniae. Finally DMSO used as negative control which showed no inhibitin zone.

Identification of the bacterial isolate number (K1) by VITEK 2.

The isolate was identified using VITEK 2 system. This system revealed that the selected isolate was similar to Klebsiella pneumoniae with 99\% probability percentage (Table 5).

\section{GC-MS analysis of cinnamon essential oil}

The results of GC-MS analysis revealed the presence of 8 peaks of different compounds with different retention times. According to this GC$\mathrm{MS}$, the major components of cinnamon essential oil was Cinnamaldehyde $(28.716 \%)$ as shown in (Fig. 3 and Table 6).
Effect of cinammon essential oil on the cell wall of Klebsiella pneumoniae

Examining Klebsiella pneumoniae cells in the control sample by TEM indicated normal structure for cell and membrane of Klebsiella pneumoniae (Fig. 4A). However, Cinnamon essential oil $(1: 5 \mathrm{v} / \mathrm{v})$ affected on the cell wall of the tested bacterium; forming some external protrusion, highly affected the bacterial morphology and led to irregular cell shape with destroyed cell wall and shrinkage of cell cavity (Fig.4B ).

\section{Histology of mice lungs}

Section of lung tissue in control mice, treated groups and cinnamon essential oil have similar structure because most of lung is composed of thin-walled alveoli. The alveoli are composed of a single layer of flattened epithelial cell (Fig 5 A, 5 D). Section of lung tissue infected with Klebsiella pneumoniae and treated with saline showed thickwall of alveoli (Fig. 5 B). Many lesions show an undoubted area of chronic collapse inflammation in which the typical structure is developing in one or more places, or even diffusely through the lesion the walls of some of the collapsed alveoli become separated and lined by a single layer of cuboidal or flattened cells. While in Fig. $5 \mathrm{C}$ section of lung tissue infected with Klebsiella pneumoniae and treated with amikacin commercial antibacterial the peribronchial connective tissue is involved in the process of chronic inflammation, it may be directly invaded by outgrowths from the lining epithelium. 
TABLE 4. Effect of different essential oils on $K$. pneumoniae isolated from patients with respiratory tract infections.

\begin{tabular}{|c|c|c|c|c|c|c|}
\hline \multirow{2}{*}{$\begin{array}{l}\text { Bacterial } \\
\text { isolate codes }\end{array}$} & Cinnamon oil & Ginger oil & Camphor oil & Pepper oil & Lavender oil & Amickacin \\
\hline & \multicolumn{6}{|c|}{ Inhibition zone diameters (mm) } \\
\hline K1 & $30 \pm 0.05$ & $11 \pm 0.00$ & $17 \pm 0.00$ & $10 \pm 0.00$ & $10 \pm 0.10$ & $057 . \pm 18$ \\
\hline $\mathrm{K} 2$ & $24 \pm 0.05$ & $20 \pm 0.00$ & $20 \pm 0.02$ & $12 \pm 0.07$ & $15 \pm 0.07$ & $10 \pm .0 .10$ \\
\hline $\mathrm{K} 3$ & $22 \pm 0.06$ & $10 \pm 0.00$ & $20 \pm 0.12$ & $15 \pm 0.16$ & $17 \pm 0.16$ & $18 \pm 0.10$ \\
\hline K4 & $24 \pm 0.05$ & $14 \pm 0.00$ & $10 \pm 0.02$ & $14 \pm 0.23$ & $15 \pm 0.23$ & $0.00 \pm 0$ \\
\hline K5 & $20 \pm 0.02$ & $14 \pm 0.00$ & $15 \pm 0.02$ & $17 \pm 0.06$ & $10 \pm 0.06$ & 00. $0 \pm 0$ \\
\hline K6 & $25 \pm 0.02$ & $11 \pm 0.00$ & $15 \pm 0.00$ & $15 \pm 0.05$ & $10 \pm 0.05$ & $0.10 \pm 18$ \\
\hline K7 & $30 \pm 0.07$ & $11 \pm 0.00$ & $17 \pm 0.11$ & $10 \pm 0.06$ & $10 \pm 0.06$ & $0.10 \pm 19$ \\
\hline K8 & $28 \pm 0.03$ & $20 \pm 0.00$ & $17 \pm 0.02$ & $18 \pm 0.03$ & $10 \pm 0.03$ & $16 \pm 0.05$ \\
\hline K9 & $26 \pm 0.05$ & $21 \pm 0.00$ & $14 \pm 0.00$ & $16 \pm 0.11$ & $12 \pm 0.11$ & 10. $12 \pm 0$ \\
\hline K10 & $22 \pm 0.00$ & $14 \pm 0.12$ & $15 \pm 0.05$ & $13 \pm 0.06$ & $12 \pm 0.06$ & $11 \pm 0.05$ \\
\hline K11 & $20 \pm 0.11$ & $10 \pm 0.00$ & $16 \pm 0.05$ & $14 \pm 0.01$ & $11 \pm 0.01$ & $10 \pm 0.10$ \\
\hline $\mathrm{K} 12$ & $19 \pm 0.02$ & $12 \pm 0.05$ & $20 \pm 0.01$ & $11 \pm 0.12$ & $10 \pm 0.12$ & $00.10 \pm 0$ \\
\hline K13 & $20 \pm 0.02$ & $14 \pm 0.05$ & $10 \pm 0.05$ & $20 \pm 0.06$ & $16 \pm 0.06$ & $0.61 \pm .20$ \\
\hline K14 & $15 \pm 0.04$ & $10 \pm 0.00$ & $10 \pm 0.14$ & $15 \pm 0.00$ & $14 \pm 0.00$ & $16.17 \pm 0$ \\
\hline K15 & $20 \pm 0.02$ & $11 \pm 0.00$ & $14 \pm 0.15$ & $15 \pm 0.00$ & $13 \pm 0.00$ & $00.0 \pm 0$ \\
\hline K16 & $16 \pm 0.11$ & $10 \pm 0.00$ & $15 \pm 0.01$ & $14 \pm 0.00$ & $13 \pm 0.00$ & $17 \pm 0.10$ \\
\hline K17 & $20 \pm 0.023$ & $10 \pm 0.00$ & $12 \pm 0.06$ & $16 \pm 0.04$ & $10 \pm 0.04$ & $10 \pm 0.05$ \\
\hline K18 & $19 \pm 0.05$ & $11 \pm 0.00$ & $20 \pm 0.00$ & $20 \pm 0.07$ & $10 \pm 0.07$ & $19 \pm 0.60$ \\
\hline K19 & $24 \pm 0.04$ & $11 \pm 0.00$ & $17 \pm 0.03$ & $22 \pm 0.03$ & $14 \pm 0.03$ & $00.10 \pm 0$ \\
\hline K20 & $23 \pm 0.03$ & $10 \pm 0.00$ & $17 \pm 0.05$ & $20 \pm 0.04$ & $15 \pm 0.04$ & $05.10 \pm 0$ \\
\hline K21 & $20 \pm 0.04$ & $10 \pm 0.10$ & $16 \pm 0.05$ & $15 \pm 0.04$ & $11 \pm 0.04$ & $17 \pm 0.60$ \\
\hline K22 & $20 \pm 0.02$ & $12 \pm 0.12$ & $14 \pm 0.00$ & $18 \pm 0.00$ & $13 \pm 0.00$ & $05.10 \pm 0$ \\
\hline K23 & $18 \pm 0.06$ & $10 \pm 0.00$ & $19 \pm 0.06$ & $18 \pm 0.02$ & $13 \pm 0.02$ & $12 \pm 0.057$ \\
\hline $\mathrm{K} 24$ & $21 \pm 0.11$ & $11 \pm 0.00$ & $18 \pm 0.02$ & $23 \pm 0.05$ & $10 \pm 0.05$ & $05.19 \pm 0$ \\
\hline $\mathrm{K} 25$ & $20 \pm 0.05$ & $11 \pm 0.00$ & $15 \pm 0.05$ & $16 \pm 0.11$ & $11 \pm 0.11$ & $10 \pm 0.05$ \\
\hline Total mean & $21 \pm 0.17$ & $12.5 \pm 0.35$ & $15 \pm 0.33$ & $16 \pm 0.02$ & $12.5 \pm 0.22$ & $61.0 \pm 12$ \\
\hline F value & 21.231 & 104.944 & 50.09 & 51.98 & 130.72 & 3020.67 \\
\hline$P$ value & 0.000 & 0.000 & 0.000 & 0.000 & 0.000 & 0.000 \\
\hline
\end{tabular}

Tested oils were diluted 1:3 using DMSO.

DMSO: represents the negative control $=0 \mathrm{~mm}$ 
TABLE 5. Confirmed identification of K. pneumoniae by VITEK2.

\begin{tabular}{|c|c|c|c|c|c|c|c|c|c|c|c|}
\hline \multicolumn{5}{|c|}{ Identification information } & \multicolumn{7}{|c|}{ Card: GN (Gram negative) } \\
\hline \multirow{2}{*}{\multicolumn{5}{|c|}{$\begin{array}{l}\text { Selected organism } \\
\text { probability percentage: } 99 \%\end{array}$}} & \multicolumn{7}{|c|}{ Klebsiella pneumoniae sp. pneumoniae } \\
\hline & & & & & \multicolumn{6}{|c|}{ Confidence: Excellent identification } & \\
\hline \multicolumn{12}{|c|}{ Bionumber: 6627734773565010} \\
\hline \multicolumn{12}{|c|}{ Biochemical details } \\
\hline 2 & APPA & - & 3 & $\mathrm{ADO}$ & + & 4 & PyrA & + & 5 & IARL & - \\
\hline 7 & $\mathrm{dCEL}$ & + & 9 & BGAL & + & 10 & $\mathrm{H}_{2} \mathrm{~S}$ & - & 11 & BNAG & + \\
\hline 12 & AGLT & - & 13 & $\mathrm{dGLU}$ & + & 14 & GGT & + & 15 & OFF & + \\
\hline 17 & BGLU & + & 18 & Dmal & + & 19 & Dman & + & 20 & Dmne & + \\
\hline 21 & BXYL & + & 22 & Balap & - & 23 & ProA & - & 26 & LIP & - \\
\hline 27 & PLE & + & 29 & TyrA & + & 31 & URE & + & 32 & Dsor & + \\
\hline 33 & SAC & + & 34 & dTAG & + & 35 & dTRE & + & 36 & CIT & + \\
\hline 37 & MNT & + & 39 & $5 \mathrm{KG}$ & + & 40 & ILATK & + & 41 & AGLU & - \\
\hline 42 & SUCT & + & 43 & NAGA & - & 44 & AGAL & + & 45 & PHOS & + \\
\hline 46 & GlyA & + & 47 & ODC & - & 48 & LDC & + & 53 & IHISa & - \\
\hline 56 & CMT & - & 57 & BGUR & - & 58 & O129R & + & 59 & GGAA & - \\
\hline 61 & IMLTa & - & 62 & ELLM & - & 64 & ILATa & - & & & \\
\hline
\end{tabular}

APPA: Ala-Phe-Pro-Arylamidase; ADO: Adonitol; PyrA: L-Pyrrolydonyl-Arylamidase; IARL: L-Arabitol; dCEL: D-Cellobiose; BGAL: Beta-Galactosidase; H2S: H2S Production; BNAG: Beta-N-Acetyl-Glucosaminidase; AGLTp: GlutamylArylamidasepNa; dGLU: D-Glucose; GGT: Gamma-Glutamyl-Tranferase; OFF: Fermentation/ Glucose; BGLU: Beta-Glucosidase; dMAL: D-Maltose; dMAN: D-Manitol; dMNE: D-Mannose; BXYL: Beta-Xylosidase; BAlap: Beta alanine ArylamidasepNa; ProA : L-ProlineArylamidase; LIP: Lipase; PLE: Palatinose; TYrA: Tyrosine Arylamidase; URE: Urease dSOR: D-Sorbitol; SAC: Saccharose/Sucrose; dTAG: D-Tagatose; dTRE: D-Trehalose; CIT: Citrate-sodium; MNT: Malonate; 5KG: 5-Keto-D-Gluconate; ILATK: L-Lactate Alkalinisation; AGLU: Alpha-Glucosidase; SUCT: Succinate Alkalisation; NAGA: Beta-N-Acetyl-Galactosaminidase; AGAL: Alpha-Galactosidase; PHOS: Phosphatase; GlyA: Glycine Arylamidase; ODC: Ornithine Decarboxylase; LDC: Lysine Decarboxylase IHISa: L-Histidine Assimilation; CMT: Coumarate; BGUR: Beta-Glucuronidase O129R: 2,4-Diamino-6,7-Diisopropylpteridine Resistance; GGAA: GluGly-Arg-Arylamidase; IMLTa: L-Malate Assimilation; ELLM: ELLMAN; ILATa: L-Lactate Assimilation.

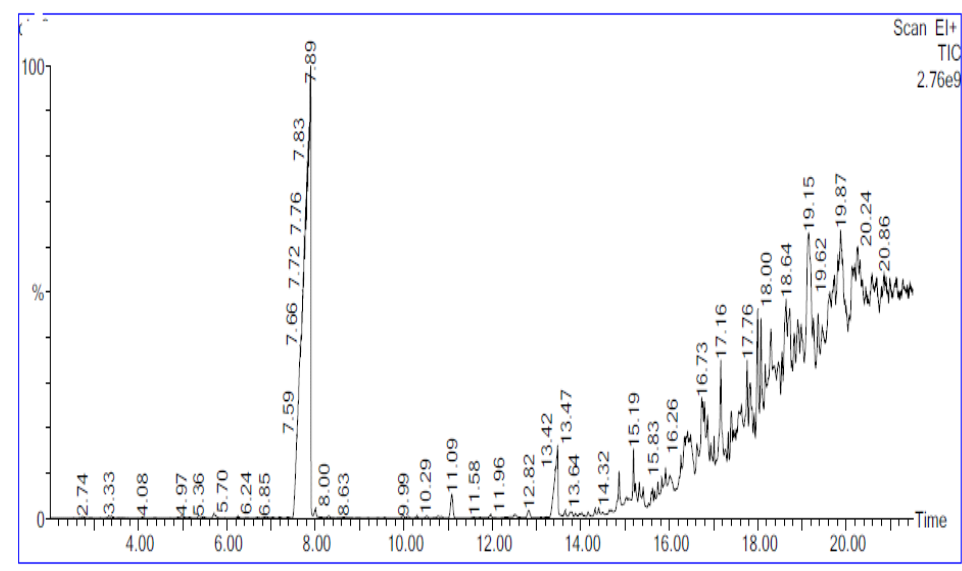

Fig 3. A. GC-MS chromatogram of cinnamon essential oil.

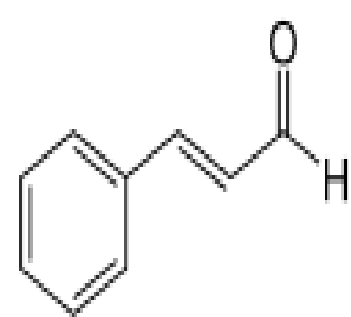

Fig. 3.B. Cinnamaldhyde (C9H8O) • 

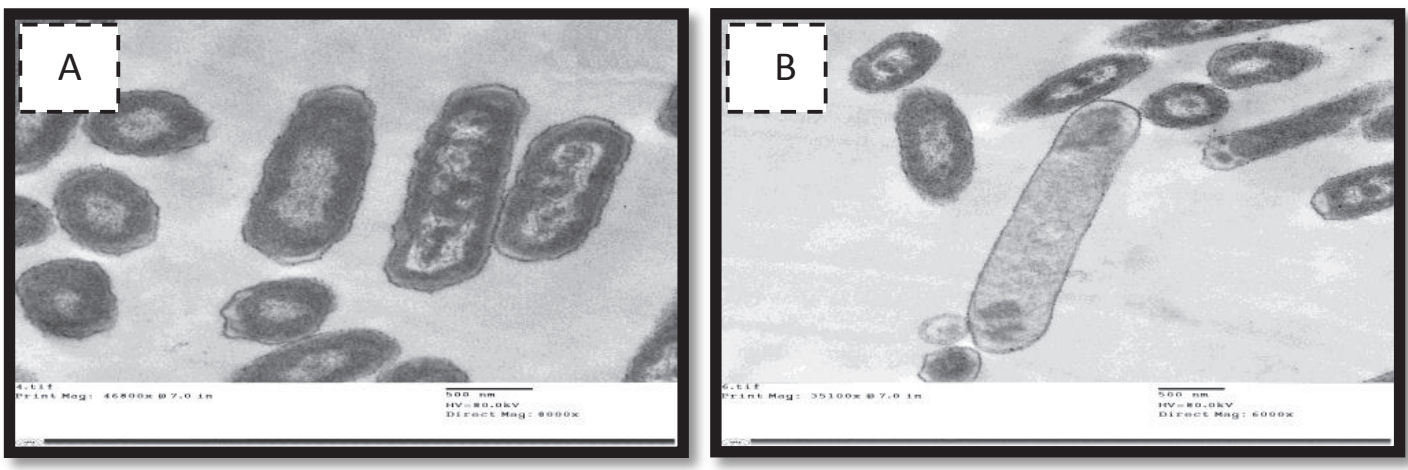

Fig.4. The electron micrograph (A) control of Klebsiella pneumoniae by transmission electron microscope. Direct Mag: 10000x showed the cells have well-defined outer cell and dense inner cell walls and intact plasma cell membranes (B) Klebsiella pneumoniae by transmission electron microscope treated with cinnamon oil Mag: 10000x showed the cell with vacuoles and ruptured of cell wall.

TABLE 6. GC-MS analysis of cinnamon essential oil.

\begin{tabular}{lccc}
\hline Peak & Retention Time (min) & \%Area & Compound \\
\hline 1 & 7.896 & 28.716 & Cinnamaldehyde \\
2 & 13.473 & 2.190 & Coumarin \\
10 & 18.295 & 1.516 & Heptacosanol \\
15 & 19.151 & 5.639 & Hexacosane, Heptadecane, \\
17 & 19.731 & 1.828 & Docosane \\
18 & 19.811 & 1.320 & Eicosane, Heneicosane \\
19 & 19.871 & 3.782 & eptadecane, Dodecanol, Ethanol \\
20 & 20.261 & 1.769 & Heneicosane \\
\hline
\end{tabular}
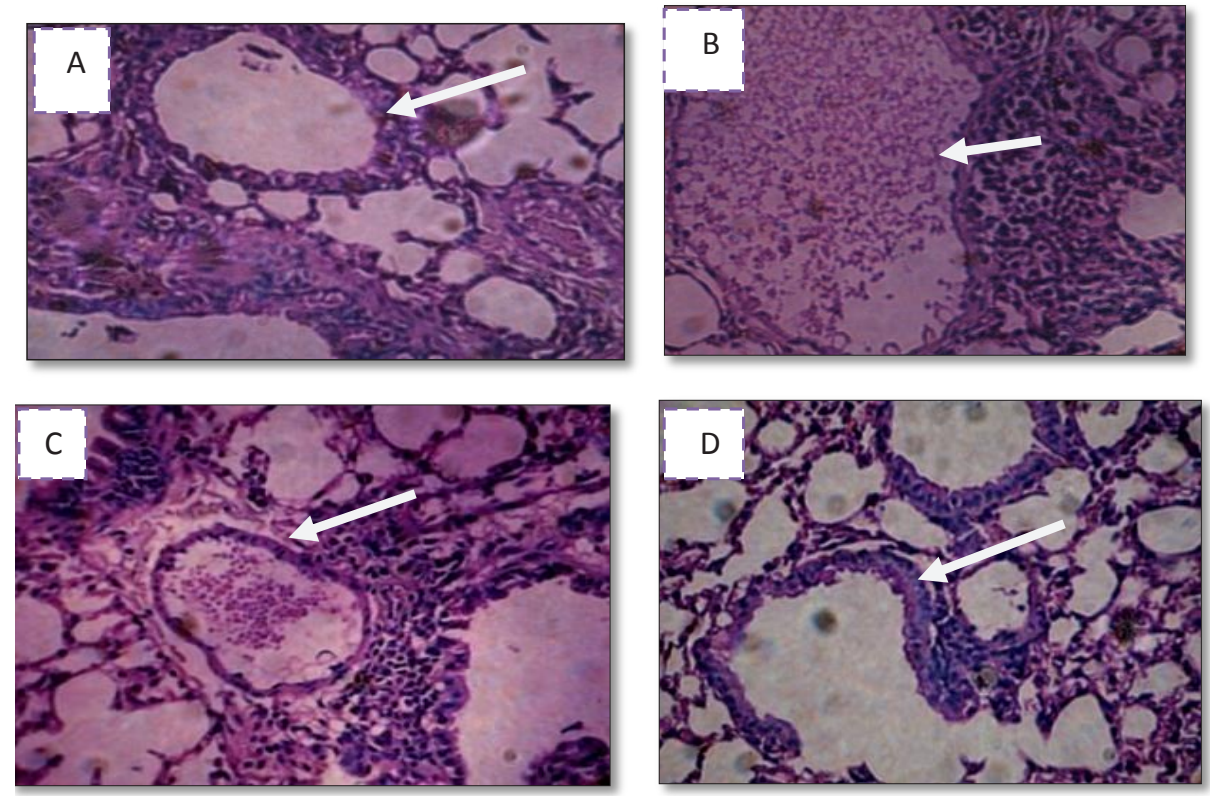

Fig. 5. Photomicrograph of H\&E-stained lung ( A) Healthy lung - (B) Lung treated with saline as a negative control after 5 days $x 40$ (C) Lung treated with Amikacin after 5 days $x$ 40. (D) Lung treated with cinnamon essential oil after 5 days $x 40$. 


\section{Discussion}

Plant essential oils and extracts have been used for many thousands of years in food preservation, pharmaceutical, alternative medicine and natural therapies (Nazzaro et al., 2013). Essential oils are potential source of novel antimicrobial compounds especially against fungal and bacterial pathogen (Swamy et al., 2015). The antimicrobial activity of EOs, similar to all natural extracts, is dependent on their chemical composition and the amount of the single components. Their antimicrobial activity is not attributable to a unique mechanism but is instead a cascade of reactions involving the entire bacterial cell. The mechanisms of action of the EOs include the degradation of the cell wall, damaging the cytoplasmic membrane, cytoplasm coagulation, damaging the membrane proteins, increased permeability leading to leakage of the cell contents, reducing the proton motive force and reducing the intracellular ATP pool via decreased ATP. Ergosterol is specific to fungi and is the major sterol component of the fungal cell membrane. It is also responsible for maintaining the cell function and integrity it has been shown that essential oils can also cause a considerable reduction in the quantity of ergosterol (Pinto et al., 2009). Factors affecting antimicrobial activity in the antimicrobial action of essential oil components, the lipophilic character of their hydrocarbon skeleton and the hydrophilic character of their functional groups are of the main importance. The results of this study showed the cinnamon essential oils had high antimicrobial activity against both $A$. flavus and $K$. pneumoniae and the high inhibitory effect due to eight constituents of the oil were identified by GC-MS techniques. The major component in the cinnamon essential oil was cinnamaldehyde and this component was reported to inhibit ATPase enzymes and disrupt the outer cell membrane (Akhtar et al., 2014) which make the changes in cell wall of tested bacteria; external disintegration and irregular cell wall was detected under TEM. The composition of the lavender EO recognized for their antimicrobial efficacy: caryophyllene (Blazeković et al., 2011) illustrate effect of lavender oil against fungi and bacteria. Camphor is the major component of camphor EO has antibacterial properties (Soković et al., 2011). The gingerol and shogaol are the major components of ginger, that could be responsible agents for the antimicrobial properties of ginger, they are phenolic compounds causing rupture of the bacterial cell membrane and loss of their properties (Masniari., 2011) and greater loss of cell contents or critical output of molecules and ions can lead to cell death (Ali et al., 2015 and Fei et al., 2017). The cinnamon essential oil presents a positive effect on the alveolar architecture. Treated groups indicated a presence of a dilatory effect on alveolar ducts, alveolar sac sand alveoli and there was no observable loss of alveolar architecture no emphysematous areas, and no alveolar congestion in the treated groups (Mauad et al., 2010 ) In the present study, the cinnamon essential oil has no bad abnormal effect on treated lungs of mice but may increase size and the dilation of alveolar sacs and alveoli compared with control. The dilatory effect may be due to increase elasticity of the elastic fibers of the supporting tissue surrounding the alveolar duct (Seiffert et al., 2015). So The cinnamon essential oil has antimicrobial activity which made inside cell and shrinkage of cell cavity due to presence of cinnamaldehyde. (Al-Mariri et al., 2014 and Roya et al., 2017).

\section{Conclusions}

It can be concluded that cinnamon essential oil has efficient antimicrobial activity. It could be recommended for pharmaceutical preparations for the treatment of microbial respiratory diseases.

Acknowledgements: The authors are thankful to staff members of the "Central Lab. of Tanta University Hospital, Egypt" for providing the clinical specimens of respiratory tract infections.

\section{$\underline{\text { Referances }}$}

Akhtar, M.S., Degaga, B. and Azam, T. (2014) Antimicrobial activity of essential oils extracted from medicinal plants against the pathogenic microorganisms: a review, Biological Sciences and Pharmaceutical Research, 2,1-7.

Ali, B., Al-Wabel, N.A., Shams, S., Ahamad, A., Khan, S.A. and Anwar, F. ( 2015) Essential oils used in aromatherapy: a systemic review. Asian Pacific Journal of Tropical Biomedicine, 5, 601-611.

Al-Mariri, A. and Safi, M. (2014) In vitro antibacterial activity of several plant extracts and oils against some gram-negative bacteria. Iranian Journal of Medical Sciences, 39, 36-43.

Anibijuwon, I..I. and Udeze, A.O. (2009) Antimicrobial activity of Carica papaya (Pawpaw leaf) on some pathogenic organisms of clinical origin from southwestern Nigeria. Ethnobotanical Leaflets. 13,850-864.

Bakkali, F., Averbeck, S., Averbeck, D. and Idaomar, M.M. (2008) Biological effects of essential oils- 
areview. Food and Chemical Toxicology, 46, 446- 475.

Blazeković, B., Stanic, G., Pepeljnjak, S. S. and Vladimir, K. (2011) In vitro antibacterial and antifungal activity of Lavandula $\mathrm{x}$ intermedia Emeric ex Loisel '.Budrovka'. Molecules, 16, 4241- 4253.

Bouzidi, N., Mederbal, K. and Raho, G.B. (2016) Antioxidant activity of essential oil of Artemisia herba- alba. Journal of Applied Environmental and Biological Sciences, 6, 59-65.

CLSI (2014) Performance standards for antimicrobial susceptibility testing; twenty third informational supplement, The Clinical and Laboratory Standards Institute, 34, 1.

Cornelia, V., Morten, S. and Amalia, C. M. (2017) Comparative analysis of the composition and active property evaluation of certain essential oils to assess their potential applications in active food packaging. Materials, 10, 45.

Denning, D.W., Clemons, KV., Hanson, L.H. and Stevens, D.A. (1990) Restriction endonuclease analysis of total cellular DNA of Aspergillus fumigatus isolates of geographically and epidemiologically diverse origin. Journal of Infectious Diseases,,162,1151-1158.

Ellis, P.H. and Griffiths, D.A. (1974) The location and analysis of melanins in the cell walls of some soil fungi. Canadian Journal of Microbiology, 20,13791386.

Fei, L., Fei, G., Qianqian, W. and Lin, L. (2017) Changes of membrane fatty acids and proteins of Shewanella putrefaciens treated with cinnamon oil and gamma irradiation. Bioresources and Bioprocessing, 4,1.

Garrity, G.M. (2001) "Bergey's Manual of Systematic Bacteriology". $2^{\text {nd }}$. ed Vol. 1, Taxonomic Outline of the Archaea and Bacteria. New York, Berlin, Heidelberg: Springer.

Kunle, O.F., Egharevba, H.O. and Ahmadu, P.O. (2012) Standardization of herbal medicines. International Journal of Biodiversity and Conservation, 4,101-112.

Lakehal, S., Meliani, A., Benmimoune, S., Bensouna, S.N. and Benrebiha, F.Z. (2016) Essential oil composition and antimicrobial activity of artemisia herba-alba Asso Grown in Algeria. Medicinal Chemistry, 6, 435-439.

Mahmoud, Y.A.., Al-Ghamdi, A.Y. and Abd El-Zaher, E.H. (2011) A protective mechanism in lungs of rats experimentllay infected with Aspergillus fumigatus.
Mycobiology, 39,40-44.

Masniari, P. (2011)The effect of red ginger (Zingiber officinale Roscoe) extract on the growth of mastitis causing bacterial isolates, African Journal of Microbiology Research, 5, 382-389.

Mauad, T., Hajjar, L.A., Callegari, G.D., da Silva, L.F. and Schout, D. (2010).Lung pathology in fatal novel human influenza A (H1N1) infection. American Journal of Respiratory and Critical Care Medicine, 181(1), 72-79.

Moubasher, A.H. (1993) "Soil Fungi in Qatar and Other Arab Countries". University of Qatar, $1^{\text {st }}$ ed. Center for Scientific, Research Qatar, pp.78-81.

Nazzaro, F., Fratianni, F., Martino, L.D., Coppola, R.V. and Feo, D. (2013) Effect of essential oils on pathogenic bacteria. Pharmaceuticals, 6,1451-1474.

Nor, R.M., Zakaria, I., Wan, I.I., Nurdiana, Z., Nor, H.R., Muhammad, N.F.R. and Nazar, M.Z.M.A. (2016) Antimicrobial activity of cinnamon oil against bacteria that cause skin infections. Journal of Scientific Research and Development, 3,1-6.

Pesavento, G., Calonico, C., Bilia, A.R., Barnabei, M., Calesini, F. and Addona, R. (2015) Antibacterial activity of oregano, rosmarinus and thymus essential oils against Staphylococcus and Listeria monocytogenes in beef meat balls. Food Control, $\mathbf{5 4 , 1 8 8 - 1 9 9 . ~}$

Pinto, E., Vale-Silva, L., Cavaleiro, C. and Salgueiro, L . (2009) Antifungal activity of the clove essential oil from Syzygium aromaticum on Candida, Aspergillus and dermatophyte species. Journal of Medical Microbiology, 58,1454-1462.

Roya, M., Atousa, A. and Hasan, R. (2017)Ultrasonic nano emulsification of food grade transcinnamaldehyde: 1,8-Cineol and investigation of the mechanism of antibacterial activity. Ultrasonics Sono Chemistry, 35, 415-421.

Seiffert, J., Hussain, F.,Wiegman, C., Li, F., Bey, L., Baker,W., Porter, A., Ryan, M,. PChang, Y., Gow, AZhang, J., Zhu, J., Tetley, T.D. and Chung, K.F.(2015) Pulmonary toxicity of instilled silver nanoparticles: Influence of size, coatingand rat strain. PLoS ONE, 10, e0119726.

Skocibu, M., Sic, N., Bezi, C., Dunki, V. and Radoni, A. '(2004) Antibacte rial activity of Achillea clavennae essential oil against respiratory tract pathogens. Fitoterapia, 75, 733-736. 
Soković, M., Glamočlija, J., Marin, P.D., Brkić, D., Van, L. and Griensven, J . (2010) Antibacterial effects of the essential oils of commonly consumed medicinal herbs using an in vitro model .Molecules, 15, 7532-7546.

Spuur, A.R. (1969) A low viscosity epoxyresin embedding medium for electron microscopy. Journal of Ultra Structure and Molecular Structure Research, 26,31-41.

Swamy, M.K. and Sinniah, U.R. (2015)A comprehensive review on the phytochemical constituents and pharmacological activities of pogostemon cablin Benth. An Aromatic Medicinal Plant of Industrial Importance Molecules, 20, 8521-8547.

Thompson, J.D., Higgins, D.G., Gibson, T.J. and Clustal, W. (1994) Improving the sensitivity of progressive multiple sequence alignment through sequence weighting, position-specific gap penalties and weight matrix choice. Nucleic Acids Research, 22, 4673-4680.

Uniyal, V., Bhatt, R.P., Seema, S. and Amitabh, T. (2012) Antifungal activity of essential oils and their volatile constituents against respiratory tract pathogens causing Aspergilloma and Aspergillosis by gaseous contact. Journal of Applied and Natural Science, 4, 65-70.

White, T.J., Bruns, T., Lee, S. and Taylor, J. (1990) Amplification and direct sequencing of fungal ribosomal RNA genes for phylogenetics. In:" $P C R$ Protocols: A Guide to Methods and Applications". Innis, M.A., Gelf and D.H. Sninsky, J.J., White, T.J. (Ed.), pp315-322. New York: Acad. Press.

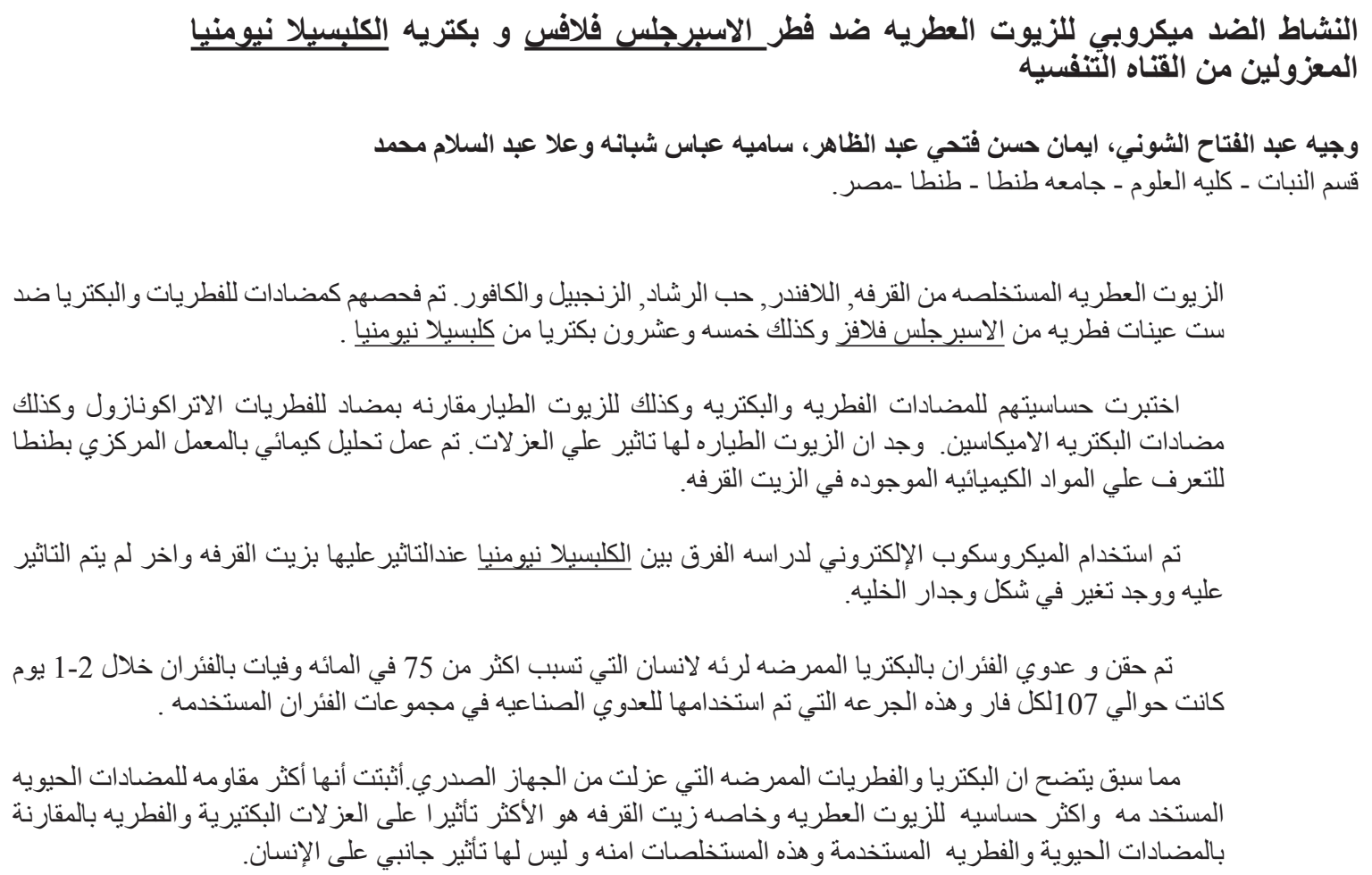

